\title{
Computational and experimental analysis of a hybrid car impact absorber
}

\author{
M. Costas $^{1}$, L. E. Romera ${ }^{1}$, J. Díaz ${ }^{1}$, S. Hernández ${ }^{1}$ \& A. Tielas ${ }^{2}$ \\ ${ }^{1}$ Structural Mechanics Group, School of Civil Engineering, \\ University of Coruña, Spain \\ ${ }^{2}$ CTAG, Automotive Technology Center of Galicia, Porriño, Spain
}

\begin{abstract}
Over the past years, car manufacturers have focused their efforts on improving the safety levels of drivers, passengers and pedestrians by a change in the conception of crashworthiness. Cars have become safer due to the improvement of the crash energy dissipation: plastic materials and specific energy absorbers are nowadays a requirement for most car manufacturers over the world. At the same time, a wide range of crash tests have been designed in order to qualify and compare the crashworthiness capabilities of different car models. Finally, and once the new car models pass these tests, manufacturers put their attention in optimizing the weight of the energy absorption system without penalizing the crashworthiness levels obtained from the tests.

This research tries to carry on accurate computational simulations of impacts against crash absorbers made of steel and several filling or wrapped materials such as PET foam, cork, polyamide with glass fibers and epoxy-carbon fiber composites. The numerical models are validated against experimental tests and simulation results are compared and correlated with the results obtained in the test facilities for some specimens, including an empty steel tube for comparative purposes.
\end{abstract}

Keywords: crashworthiness, crushing, hybrid parts, optimization, drop tower test.

\section{Introduction}

Occupant safety and protection systems have risen as one of the foremost research fields in automotive engineering. In particular, improvements on the 
field of crashworthiness and impact energy dissipation systems have a direct effect on the global security of vehicles. These improvements are usually affecting the configuration of the frontal car devices, especially those in which a variation of material properties or allocation can lead to a better response in case of frontal crash. Frontal crashes produce nowadays $50-70 \%$ of the fatalities by car accidents in developed countries [1]; therefore, any security improvement in this field has a direct effect on the occupant safety levels.

Devices specifically designed for frontal impact energy absorption are located between the bumper and the chassis (fig. 1). Usually, these devices consist of a hollow steel beam, with circular or rectangular section, which collapses in axial crushing dissipating part of the impact energy by plastic behaviour.

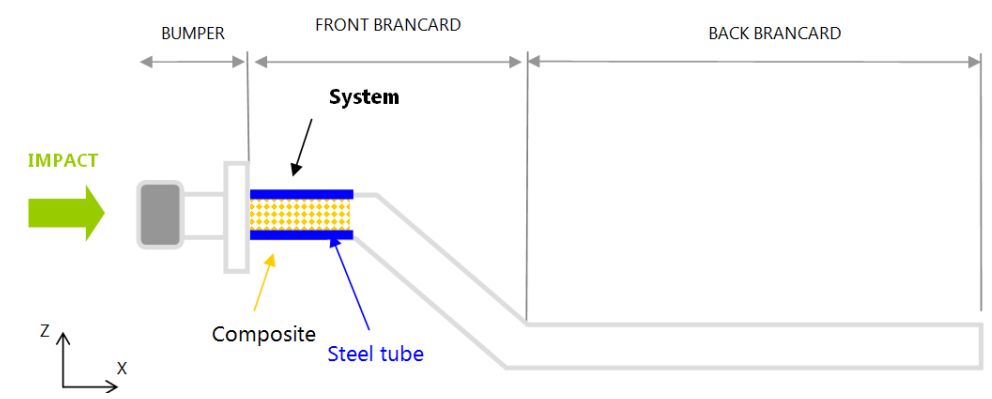

Figure 1: $\quad$ System configuration and location of dissipative device.

The mechanics of axial collapse of metal thin-walled tubes is well established, with a large number of experimental, analytical and numerical researches on the subject [2-5]. To increase the capacity of energy dissipation and crushing strength, new materials replacing steel tubes as CFRP [6], GFRP [7], or a combination of steel tubes with other materials can be regarded.

Hybrid structural elements, which are defined as a combination of a metallic enclosure surrounding a core filled with other materials, such as cork [8], synthetic foams [9] or carbon and glass FRP, can be considered as one of the best configurations when it comes to crash energy absorption. The function of the steel tube is to lodge the core and to serve as the main stress trajectory, whereas the core works increases the dissipation of the impact energy. The metallic part of these elements is usually a cold-formed steel or aluminium tube which requires welding processes to assemble the final design. Another option to increase the energy absorption of a metallic tube is to wrap it with other materials as GFRP or CFRP [10, 11]. In this study we have conducted firstly a reliable numerical simulation of the axial crushing of a circular hollow section made of steel which has been successfully compared with experimental results obtained by Abramowicz and Jones [2].

Secondly a hybrid system consisting of a steel enclosure filled with different core materials is studied numerically and experimentally. Amongst all possible alternatives for the core, the following materials have been selected: carbon-fiber reinforced polymer, glass-fiber reinforced polyamide, polyethylene terephthalate 
foam and natural cork conglomerate. Different shapes have also been considered for the core to maximize energy absorption, depending on the mechanical properties and the manufacturing processes applied to each material. This way, cork and foam cores fill up all the enclosure while polyamide and fibre reinforced cores are assembled using small pieces of plate and shell geometry. In order to obtain precise evaluations of the crashworthiness response, a finite element model has been developed, analyzed under quasi-static and dynamic explicit simulations and compared with the experimental results. Several crash parameters, such as specific energy absorption, mean crushing load, absorbed energy and load ratio are obtained from the simulations.

Thirdly a steel tube wrapped with CFRP was numerically analyzed considering the steel tube only, the CFRP tube only and the hybrid system perfectly bonded.

\section{Methodology}

The numerical FEM simulations have been carried out using ABAQUS software [12]. Thin-walled steel tubes are modelled using 4-nodes shell elements with three integration points through their thickness and reduced integration, the tubes are crushed between rigid shell plates, one fixed and other moving towards the specimen at the selected speed. Composite shell elements are used for the CFRP core or envelope, and 3D linear solid elements for foam and cork models. To achieve realistic results, geometrical and material non-linear effects, contacts, strain rate dependent effects, geometric imperfections and residual stresses have been taken into account and introduced in the numerical models for slow and high speed loads.

Mesh size is a crucial parameter when simulating metal folding processes, as its value should allow the mesh to adapt itself to the curvatures of the shell. These analyses involve important plasticity behaviour, contacts and other nonlinearities, so an extremely refined mesh can lead to unaffordable computation times. The effect of the size of the mesh elements in the numerical results was studied considering the sensitivity of the results to different element sizes; in all cases a shell size of $2 \times 2 \mathrm{~mm}$ enables an accurately simulation of the steel folding process.

Static and dynamic analyses were made using the explicit method. Despite of requiring longer times to complete the calculations when applying a low-speed load, this method ensures a reliable convergence of the mesh under very large deformations and rotations, provided that some conditions (related to energy rates and mass scaling) are satisfied. In case of the dynamic analysis, explicit method is the only affordable way to obtain accurate results in a reasonable amount of time for this kind of impact tests.

Regarding the materials, a Johnson-Cook plasticity model [13] have been calibrated for the steel tubes made of S-275 J0H steel (Elastic modulus $\mathrm{E}=2.1 \mathrm{GPa}$, yield strength $\sigma_{\mathrm{y}}=275 \mathrm{MPa}$, Poisson's ratio $v=0.3$ and density $\rho=7.85 \mathrm{t} / \mathrm{m}^{3}$ ), which is proved to be one of the best constitutive models for 
investigations involving high-speed impacts due to the introduction of parameters related to the strain rate (1).

$$
\sigma_{y}=\left[A+B\left(\varepsilon_{e f f}^{p}\right)^{N}\right](1+C \ln \dot{\varepsilon})\left[1-\left(T_{H}\right)^{M}\right]
$$

where $\mathrm{A}$ is the yielding stress and $\mathrm{B}, \mathrm{C}, \mathrm{N}$ and $\mathrm{M}$ are constants affecting the hardening law, the strain-rate dependency, the shape of the hardening law and the temperature dependency respectively. The strain-rate ratio is defined as

$$
\dot{\varepsilon}=\frac{\varepsilon_{e f f}^{p}}{\dot{\varepsilon}_{o}}
$$

After comparison with experimental results the values considered, disregarding temperature effects, are: $\mathrm{A}=275 \mathrm{MPa}, \mathrm{B}=50000, \mathrm{C}=0.03, \mathrm{~N}=$ 0.4 and $\dot{\varepsilon}_{o}=0.0001$. As well as this plasticity model, a ductile failure criterion and damage evolution parameters for the steel have been introduced with the purpose of removing from the numerical analysis those elements which have reached their energy dissipation limits. A value of $\varepsilon_{\mathrm{u}}=0.35$ has been taken for the ultimate strain, applying a total stiffness loss to those elements which effective strain overpasses this value.

\section{Steel tube subjected to axial dynamic crushing}

The steel tube consists of a circular hollow section with radius $28.032 \mathrm{~mm}$, length $178 \mathrm{~mm}$ and $1.2 \mathrm{~mm}$ thick (fig. 2(a)). It can be compared with specimens T3 and T4 in Abramovicz's paper [2]. This piece is impacted by a mass of $73.6 \mathrm{~kg}$ at a speed of $10.326 \mathrm{~m} / \mathrm{s}$, the resulting collapse mode is a concertina mode (fig. 2(b)).

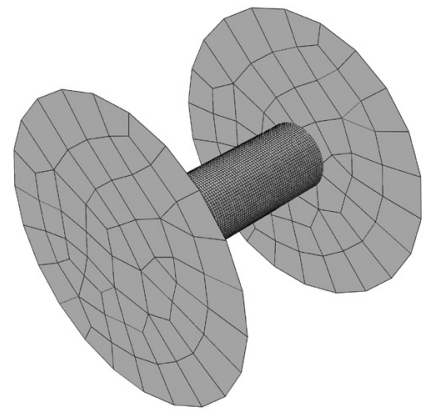

(a)

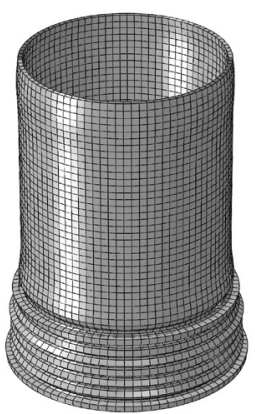

(b)

Figure 2: $\quad$ Structural mesh (a) and final deformation (b). 
The absorbed energy calculated from the numerical results by an integration of the force-displacement curve obtained in the analysis (fig. 3) has a value of $3.92 \mathrm{~kJ}$, in coincidence with the experimental value of $3.922 \mathrm{~kJ}$.

Once the numerical model is verified, the influence of the shell thickness in the final SEA (Specific Energy Absorption) defined as the quotient of the absorbed energy and the specimen mass was studied. As predicted in references [2], with more thickness the crushing mode is a transition from concertina (first lobes) to diamond (last ones) (fig. 4). As thickness increases, SEA does it too in a quasi linear function.

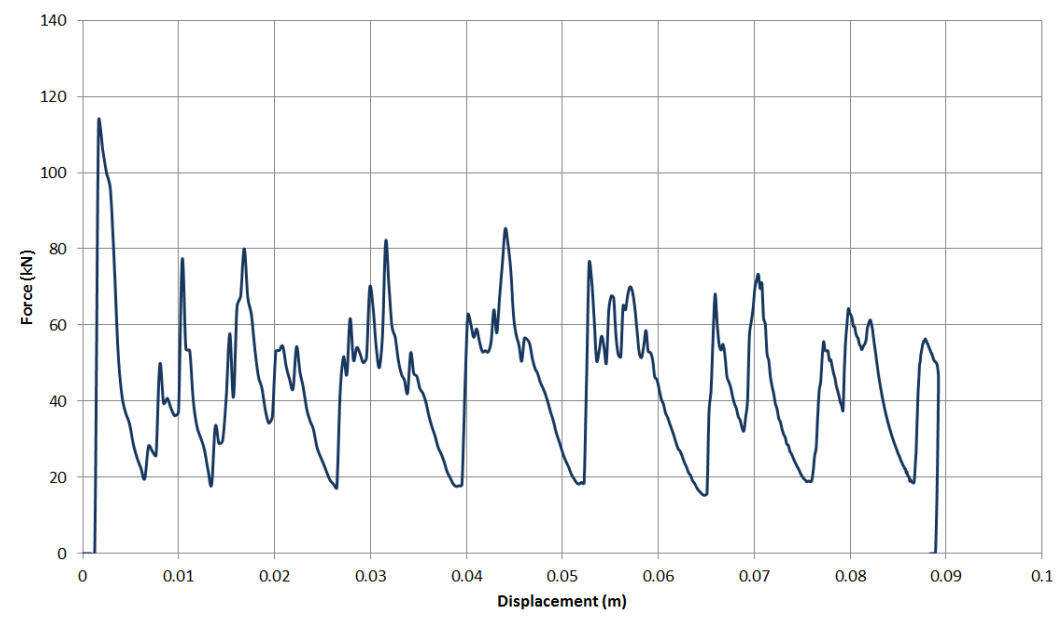

Figure 3: $\quad$ Force (KN)-displacement (m) curve.

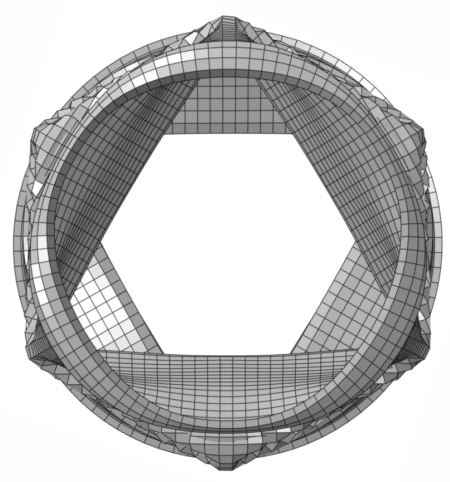

(a)

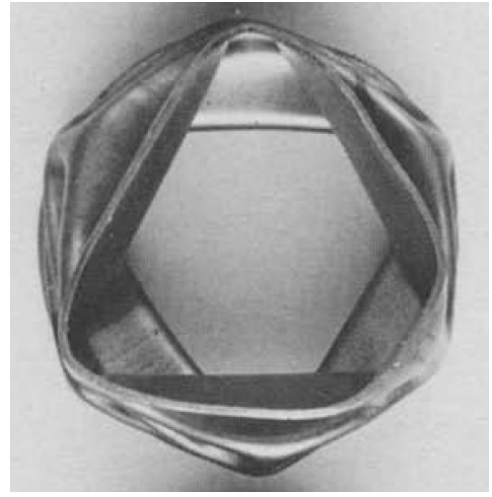

(b)

Figure 4: Concertina/diamond crushing mode: numerical (a) and experimental (b) results. 


\section{Hybrid systems}

The basic dimensions of the specimen steel tube section and the finite element mesh developed are shown in figure 5 . The thickness of the steel tube is $1 \mathrm{~mm}$, and the length is $250 \mathrm{~mm}$.

Residual plastic strains due to cold forming process and geometric imperfections with a maximum transversal displacement of $0.95 \mathrm{~mm}$, and a distribution obtained from buckling modes were applied to the mesh. Welds are modelled as a rigid joint connection between both sheets on the indicated points.
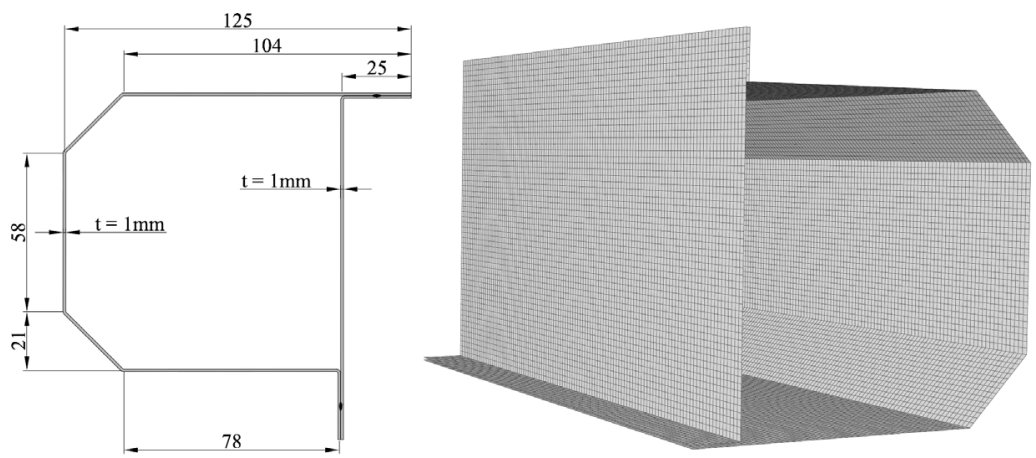

Figure 5: Finite element model and sectional dimensions (mm).

The work starts verifying the results of the numerical simulations and comparing them with the results obtained in the test facilities for all the differently filled specimens, starting with the steel tube alone. Laboratory tests consist of a standard low-speed compression loading of the tube and a drop tower test (fig. 6). In the drop tower a mass of $350 \mathrm{Kg}$ is dropped from a height of $2.5 \mathrm{~m}$, impacting the specimen at $6.7 \mathrm{~m} / \mathrm{s}$.
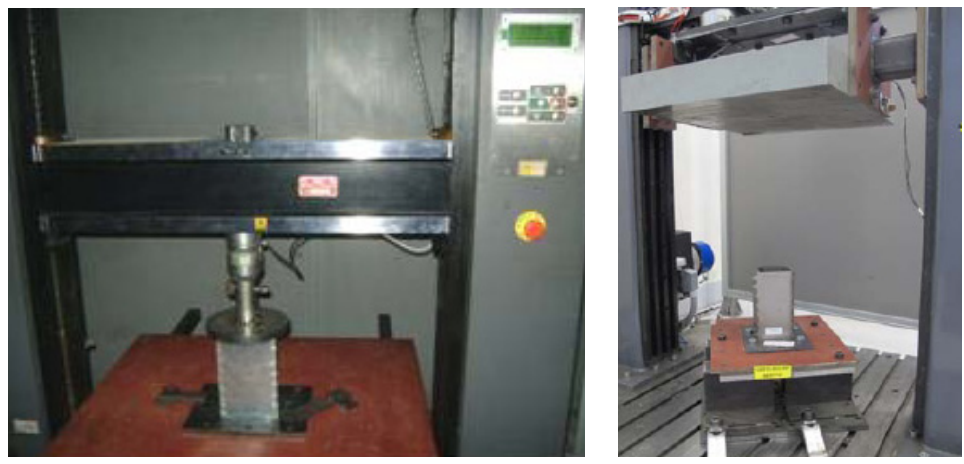

Figure 6: $\quad$ Static and impact tests.

The selected PET foam core (fig. 7(a), was AramadForm W/AC135 (Armacell), and was modelled through a crushable foam constitutive model with: 
$\mathrm{E}=90 \mathrm{MPa}, v=0.1, \rho=0.135 \mathrm{t} / \mathrm{m} 3, \mathrm{k}_{\mathrm{c}}=1.5, \mathrm{k}_{\mathrm{t}}=1$ and $\sigma_{\mathrm{y}}=2.5 \mathrm{MPa}$. In the case of the cork core, a low density foam model has been selected, and an experimental compression test has been carried out on the cork specimen to obtain the force-displacement data required for the material model.

The core of CFRP was made with four undulated laminates, each of them made from eight unidirectional pre-pegs with an individual thickness of $0.301 \mathrm{~mm}$, arranged in a stacking sequence [0/90/45/0/-45/45/90/0] (fig 7(b)). The elastic properties of this material are $E_{1}=150.67 \mathrm{GPa}, E_{2}=9.32 \mathrm{GPa}$, $\mathrm{G}_{12}=2.54 \mathrm{GPa}$ and $\mathrm{v}_{12}=0.3$. A damage model based on Hashin's theory has been implemented.

The core of GFRP consists in laminates of Ultramid A3WG10 BK00564 (Basf) with a thickness of $2.5 \mathrm{~mm}$ (fig 7(c)). A linear elastic model with fragile failure has been selected as constitutive model $(\mathrm{E}=10.16 \mathrm{GPa}, v=0.4, \rho=1.55$ $\mathrm{t} / \mathrm{m}^{3}, \sigma_{\mathrm{u}}=254 \mathrm{MPa}$ and $\varepsilon_{\mathrm{u}}=2.6 \%$ ), considering a modified ductile failure model without displacement after fragile failure and automatically deleting those elements which overpass the failure strain.

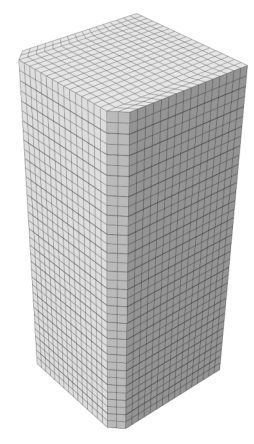

(a) Cork and PET foam core

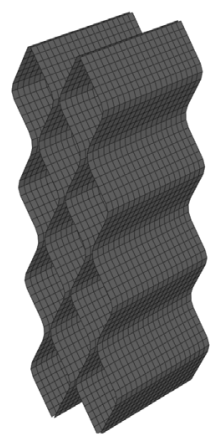

(b) CFRP core

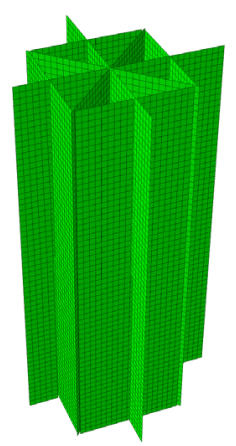

(c) GFRP core

Figure 7: $\quad$ Finite element meshes for each core.
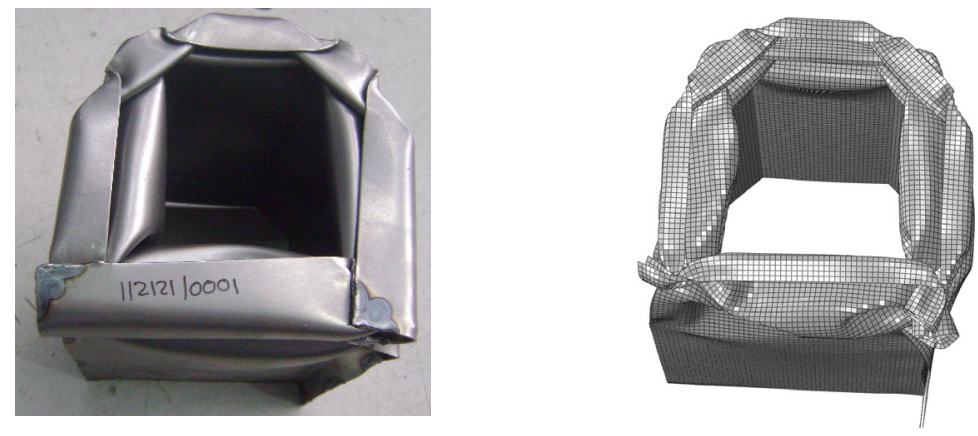

Figure 8: Numerical results. 
Final deformed configurations in the quasi-static case obtained from experimental tests and numerical results for the steel tube (fig. 8), the GFRP core (fig. 9), and the PET foam core (fig. 10), showed a good correlation between numerical results and experimental tests with crushing modes and core behaviour very similar in both results.
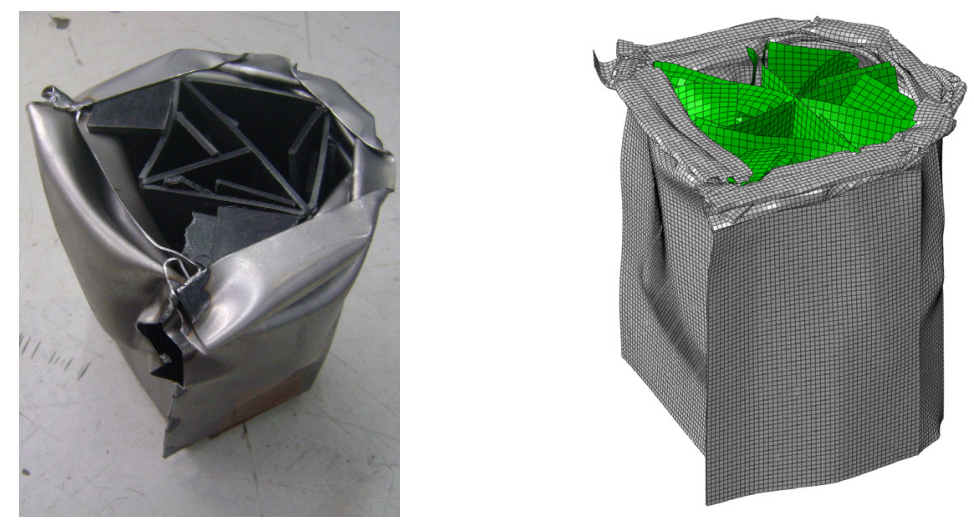

Figure 9: $\quad$ Final deformed configuration for the steel tube with GFRP core and numerical results.
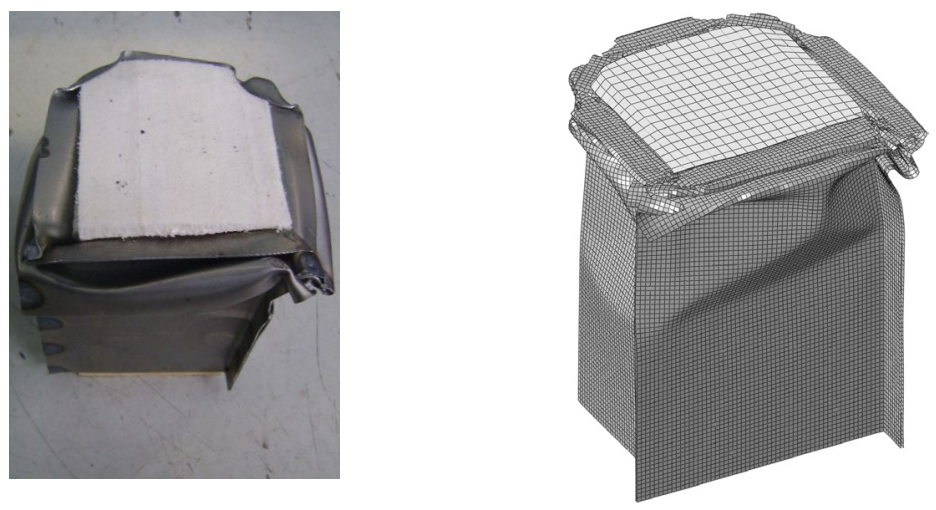

Figure 10: Final deformed configuration for the steel tube with PET foam core and numerical results.

Force-displacement curves for the numerical quasi-static simulations and the experimental test are shown in figures 11 and 12. 


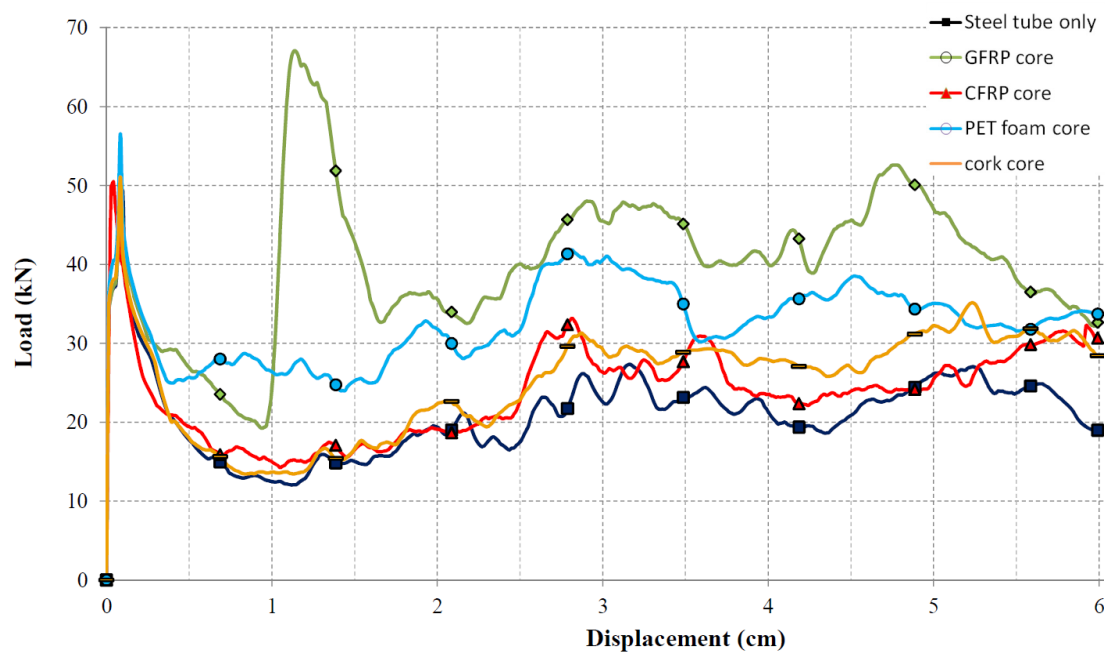

Figure 11: Numerical force-displacement results in quasi-static test.

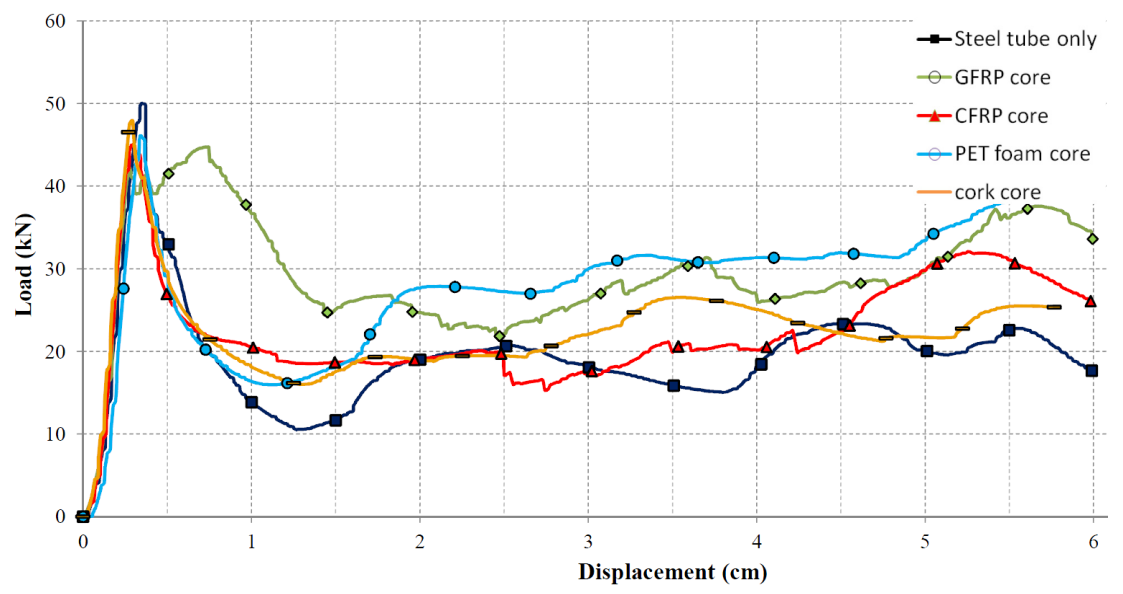

Figure 12: Numerical force-displacement results in quasi-static test.

Differences between experimental tests and numerical simulation are due to some spot weld failure in experimental test, obtaining lower forces in experimental results. Maximum SEA parameter was obtained for GFRP core with a value of $7.39 \mathrm{~kJ} / \mathrm{kg}$ for numerical results. The load ratio (maximum peak force/mean force value) for GRFP core is the minimum with a value of 1.68 ensuring a lower level of acceleration peak on the passenger. In the case of steel tube only the results obtained are SEA $=6.11 \mathrm{~kJ} 7 \mathrm{Kg}$ and load ratio of 2.37 .

In the case of dynamic tests maximum the best behaviour was obtained also for the GFRP core with a value of SEA of $6.81 \mathrm{~kJ} / \mathrm{kg}$ and load ratio of 1.37 . 


\section{Steel tube wrapped with CFRP}

In this case the same tube of paragraph 3 with $1.2 \mathrm{~mm}$ of thickness is wrapped with a composite material made of carbon fibers and epoxy. The sheet of CFRP is $2.4 \mathrm{~mm}$ thick with an inner configuration of eight plies stacked in an initial sequence [0/90/45/0/-45/45/90/0] with the same mechanical properties of the previous CFRP core. The CFRP is firmly joined to the steel part assuming that both parties are perfectly bonded.

Numerical simulations considering the steel tube only, the CFRP tube only and the hybrid system perfectly bonded has been run to find up the contribution of the interaction steel-composite to the final amount of absorbed energy, imposing a quasi-static displacement of $120 \mathrm{~mm}$ in the system.

The results obtained in the three simulations are shown in figures 13 and 14 . The absorbed energy has a value of $4.92 \mathrm{~kJ}$ for the steel tube only, $0.8 \mathrm{~kJ}$ for the CFRP tube and $11.8 \mathrm{~kJ}$ for the hybrid system, which shows the good performance of this type of reinforcement.

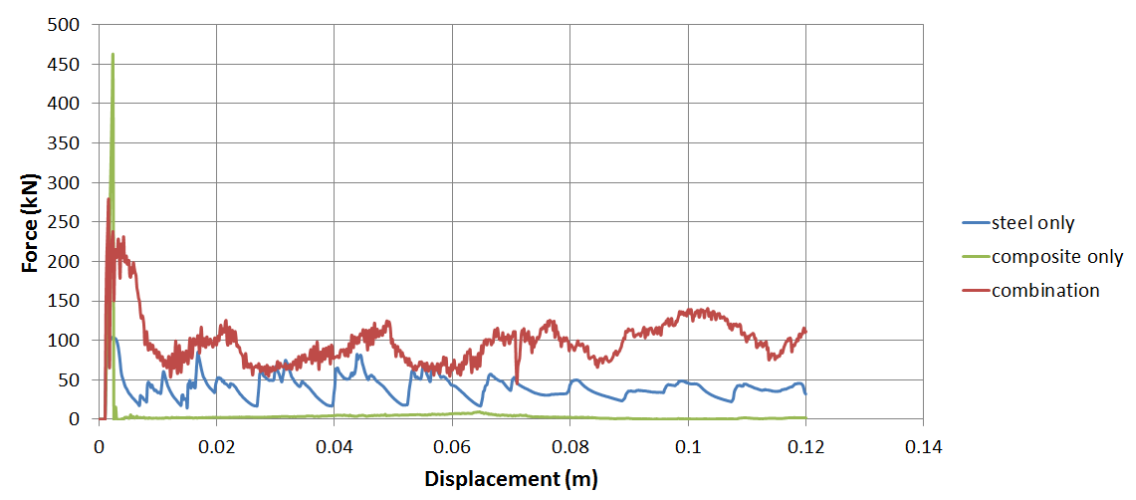

Figure 13: $\quad$ Force-displacement curves.

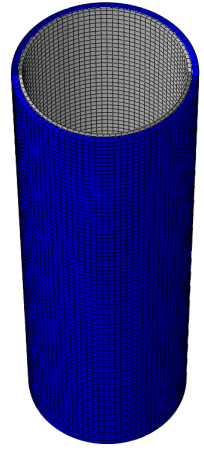

FEM model

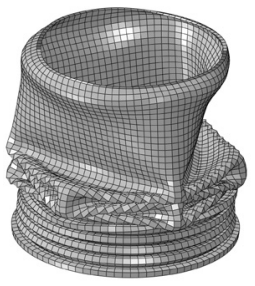

Steel only

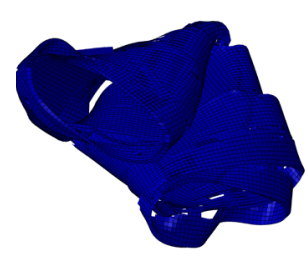

CFRP only

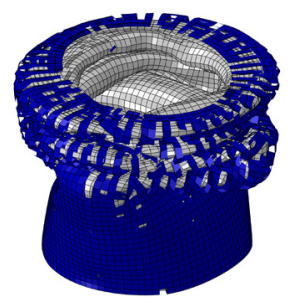

Hybrid system

Figure 14: Finite element model and final deformed configurations. 


\section{Conclusions}

Several different configurations of frontal car crash absorber have been analyzed in experimental test and numerical simulations with a correct similarity between both results.

Differences between experimental and numerical results are due mainly to defects in the steel tube welding, which reduces the rigidity in the experiments of specimens.

In the case of hybrid systems formed by a metallic enclosure surrounding a core filled with other materials, the best results experimental and numerical are obtained with GFRP laminates for the core, with significant increases in the specific energy absorption and important reductions in the load ratio. The only configuration studied of GRFP sheets gives the best results, but other configurations as honeycomb made by injection could give better results.

Considering the cost of each core, PET foam filled tubes are an option to take into account, as materials and production costs should be more affordable than GFRP laminates.

In the case of steel tubes wrapped with CFRP, the synergistic effect is important and the results of the hybrid system are excellent assuming perfectly bonded connection. More complex simulations considering the bonding behaviour and experimental tests must be developed.

Computation was carried out in a High Performance Computing (HPC) cluster with a theoretical peak performance of 5.1 TFLOP's. Numerical results were obtained using double precision explicit analyses with eight parallel processors, each one computing one of the eight domains in which the problems have been divided, with 3 gigabytes of RAM assigned to each processor. This 8p 8-d configuration has been proved to be the optimum for these problems, being eight hours the maximum time of calculation for the problems presented.

\section{Acknowledgements}

The research leading to these results has received funding from Galician Government (Xunta de Galicia) under the plan PEME I+D (Plan Galego de Investigación, Desenvolvemento e Innovación Tecnolóxica) and INCITE09, project references 10DPI025CT and 09DPI011118PR. The authors fully acknowledge the support received.

\section{References}

[1] Fatalities in frontal crashes despite seat belts and air bags. National Highway Traffic Safety Administration NHTSA. Technical report, U.S. Department of Transportation, 2009.

[2] Abramowicz, W. \& Jones, N., Dynamic axial crushing of circular tubes. International Journal of Impact Engineering, 2(3), pp. 263-281, 1984. 
[3] Abramowicz, W. \& Jones, N., Dynamic progressive buckling of circular and square tubes. International Journal of Impact Engineering, 4(4), pp. 243-270, 1986.

[4] Liu, Y., Crashworthiness design of multi-corner thin-walled columns. ThinWalled Structures, 46(12), pp.1329-1337, 2008.

[5] Gregory, N., Impact and energy absorption of straight and tapered rectangular tubes. PhD Thesis, Queensland University of Tech., 2005.

[6] Mamalis, A.G., Manolakos, D.E., Ioannidis, M.B. \& Papapostolou, D.P., The static and dynamic axial collapse of cfrp square tubes: Finite element modelling. Composite Structures, 74(2), pp. 213-225, 2006.

[7] Hamouda, A.M.S., Saied, R.O. \& Shuaeib, F.M., Energy absorption capacities of square tubular structures. Journal of Achievements in Materials and Manufacturing Engineering, 24(1), pp. 36-42, 2007.

[8] Paulino, M., Teixeira-Dias, F., Gameiro, C.P. \& Cirne, J., Hyperelastic and dynamical behaviour of cork and its performance in energy absorption devices and crashworthiness applications. International Journal of Materials Engineering Innovation, 1(2), pp. 197-234, 2009.

[9] Zhang, J., Kikuchi, N., Li, V., Yee, A. \& Nusholtz, G., Constitutive modeling of polymeric foam material subjected to dynamic crash loading. International Journal of Impact Engineering, 21(5), pp. 369-386, 1998.

[10] De Kanter, J.L., Energy absorption of monolithic and fibre reinforced aluminium cylinders. PhD. Thesis, Tech. University Delft, 2006.

[11] Song, H.W., Wan, Z.M., Xie, Z.M. \& Du, X.W., Axial impact behavior and energy absorption efficiency of composite wrapped metal tubes. International Journal of Impact Engineering, 24(4), pp. 385-401, 2000.

[12] ABAQUS 6.11 Documentation. Dassault Systèmes, 2011.

[13] Cook, G.R. \& Johnson, W.H., A constitutive model and data for metals subjected to large strains, high strain rates and high temperatures. Proceedings of Seventh International Symposium on Ballistics, pp. 541547, 1983. 